\title{
A 28,000 Year $U_{37}^{K '}$ Sea-Surface Temperature Record of ODP Site 1202B, the Southern Okinawa Trough
}

\author{
Meixun Zhao ${ }^{1,2, *}$, Chi-Yue Huang ${ }^{1}$ and Kuo-Yen Wei ${ }^{3}$ \\ (Manuscript received 17 March 2004, in final form 8 November 2004)
}

\begin{abstract}
An $U_{37}^{K^{\prime}}$ sea-surface temperature (SST) record of the last $28 \mathrm{kyr}$ has been obtained for ODP Site $1202 \mathrm{~B}\left(2^{\circ} 48.24 ' \mathrm{~N}, \mathrm{122}^{\circ} 30^{\prime} \mathrm{E}\right.$; water depth 1274 $\mathrm{m})$, drilled offshore of NE Taiwan in the southern part of the Okinawa Trough. This millennial-scale record reveals a glacial-interglacial SST difference of $5^{\circ} \mathrm{C}$, larger than SST changes at similar latitude of the open Pacific Ocean, but is similar in amplitude with SST changes of the western Pacific's marginal seas, such as the northern South China Sea (SCS). Comparison with a planktonic oxygen isotope record from the same site reveals that the last deglaciation warming was synchronous with ice volume changes, but lagged the warming in Greenland's ice core record and in the monsoon record from the Hulu Cave of Eastern China. The enhanced glacial cooling for this site was likely caused by several factors, including the variability of the Kuroshio, sea level variations, and coastline shift.
\end{abstract}

(Key words: Sea surface temperature, $\mathbf{U}_{37}^{\mathrm{K}^{\prime}}$, Kuroshio, Okinawa Trough)

\section{INTRODUCTION}

The low latitude western Pacific Ocean is a critical region for climate studies for several reasons (Cane 1998; Lea et al. 2000; Pierrehumbert 2000; Stott et al. 2002; Visser et al. 2003). The equatorial western Pacific is situated within the western Pacific Warm Pool (WPWP), which is the most important source region for transporting heat and moisture to the atmosphere and northward to the high latitude region to modulate global atmospheric circulation. The WPWP regions also provide the most significant influences on inter-annual and decadal

\footnotetext{
${ }^{1}$ Department of Earth Sciences, National Cheng kung University, Tainan, Taiwan, ROC

2 Department of Earth Sciences, Dartmouth College, Hanover, New Hampshire, USA.

3 Department of Geosciences, National Taiwan University, Taipei, Taiwan, ROC

* Corresponding author address.Prof. Meixun Zhao, Department of Earth Sciences, National Cheng kung University, Tainan, Taiwan, ROC; E-mail: Meixun.Zhao@Dartmouth.edu
} 
climate oscillations such as El Niño and La Niña, both in the Pacific and extra-tropical regions (Cane 1998; Pierrehumbert 2000; Hoerling et al. 2001; Hoerling and Kumar 2003). In addition, seawater in this region is the source for the Kuroshio, which is equally important in transporting heat and salt from the WPWP region to high latitudes. Finally, the heat capacity difference of the ocean and Asia continent is the main mechanism driving the summer and winter monsoons, which dominate climate for this region.

Much attention has been focused on the role of the tropics in driving past global climate changes, especially with regard to the magnitude and timing of tropical climate changes in relation to changes in other regions (Lea et al. 2000; Kienast et al. 2001; Stott et al. 2002; Visser et al. 2003). Some records suggest that SST warming leads ice volume (Lea et al. 2000), but other suggest almost synchronous changes (Kienast et al. 2001). It is clear that more high-resolution records on millennial and orbital scales are needed for a better understanding of these phase relationships.

Another unresolved question concerning the western Pacific Ocean is the strength and pathway of the Kuroshio during the late Quaternary. Presently, the source of the Kuroshio is within the WPWP and flows northward along the east coast of Taiwan (Nitani 1972). It becomes a well-defined western boundary current off eastern Taiwan, and its flow intensifies after it passes through the channel between Taiwan and the southernmost part of the Ryukyu Island Arc. The Kuroshio continues to flow northeastward along the northern slope of the Okinawa Trough, before being deflected eastward offshore of central Japan. The Kuroshio is a relatively narrow $(150-200 \mathrm{~km})$ and deep $(\sim 600 \mathrm{~m})$ surface current (Fan 1985). It transports a large amount (Yuan et al. 1998) of warm and salty equatorial seawater northward and contributes eventually to the formation of North Pacific Intermediate Water.

A direct SST record near Kuroshio's source region does not exit, but estimates based on planktonic $\delta^{18} \mathrm{O}$ show a cooling of $3^{\circ} \mathrm{C}$ during the last glacial period (Ujiié et al. 2003). Transfer function methods revealed large winter temperature decreases (up to $10^{\circ} \mathrm{C}$ ) during the last glacial maximum for the southern Okinawa Trough (Li et al. 1997). Several records from the mid- to upper reach of the Kuroshio indicate various degrees of cooling during the last glacial phase. Swada and Handa (1998) attributed most of the SST changes to the meandering patterns of the Kuroshio, instead of the changes in the Kuroshio's source region SST or its strength. Others proposed that most of the SST changes were caused by the changed pathway of the Kuroshio due to sea level changes, which prevented the Kuroshio from entering into the Okinawa Trough (Ujiié and Ujiié 1999; Li et al. 2001; Ujiié et al. 2003). Preliminary $\mathrm{U}_{37}^{\mathrm{K}}$ SST results from IMAGES core MD012419 (Zhao and Huang 2003) and MD012421 (Yamamoto and Irino 2003) indicate that these northern sites were relatively warm during the LGM, suggesting a strong Kuroshio. On the other hand, SST was much colder (by $8-10^{\circ} \mathrm{C}$ ) during the deglaciation, indicating a lack of Kuroshio influence for these sites.

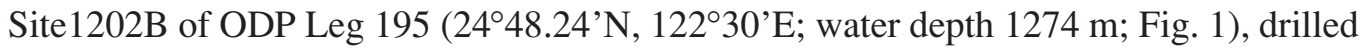
offshore of NE Taiwan in the southern part of the Okinawa Tough, is near the northern limit of the WPWP SST boundary $\left(28^{\circ} \mathrm{C}\right)$ and the source region of the Kuroshio. The main objective for drilling Site 1202 was to obtain high sedimentation rate cores for high-resolution reconstruction of the variability of the Kuroshio during the late Quaternary. Stratigraphic studies have indicated that the upper $110 \mathrm{~m}$ has a continuous record of the past 28 thousand years for 


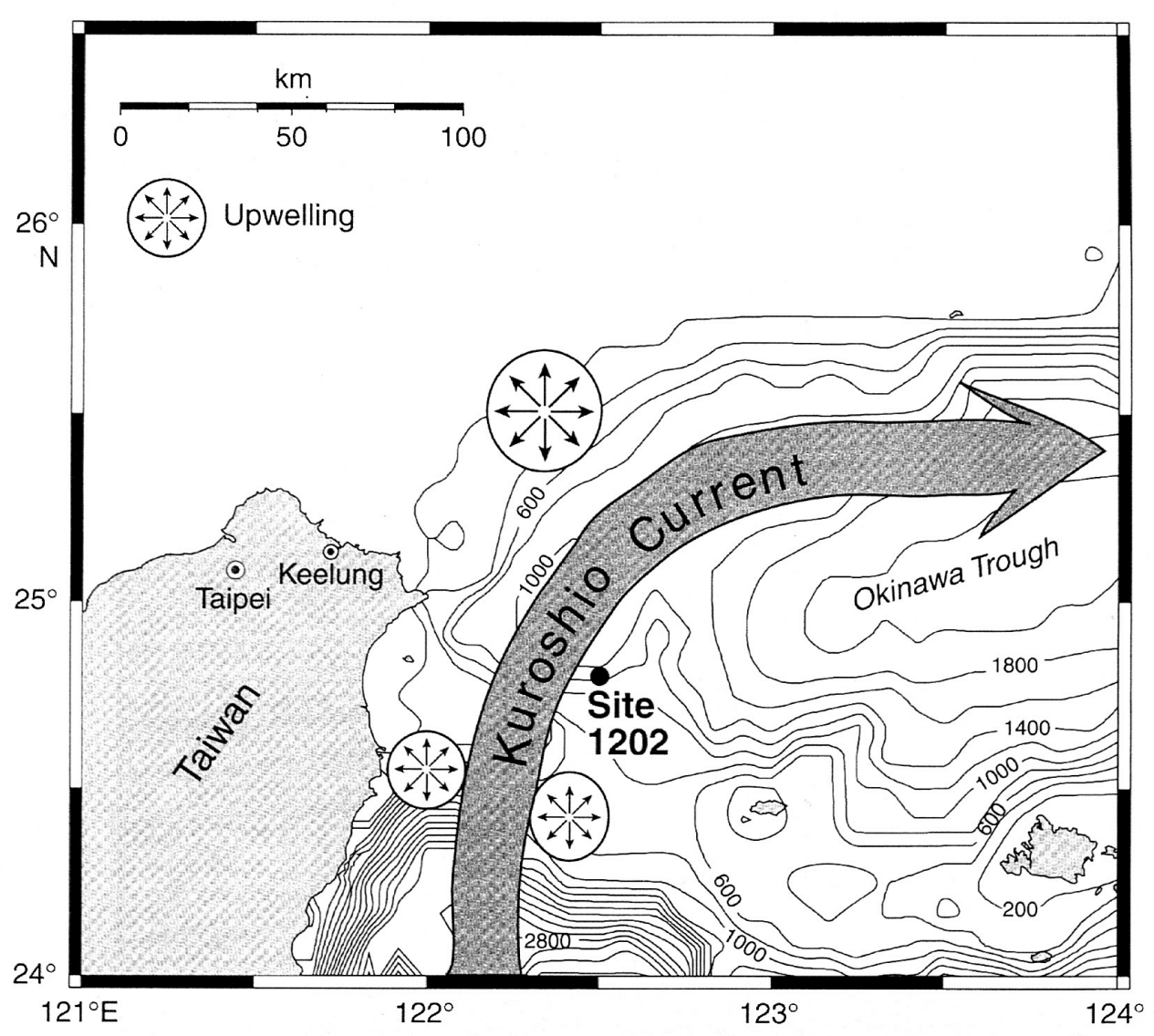

Fig. 1. A map showing the ODP Site 1202. The Kuroshio is indicated by the arrow in the western Pacific (Shipboard Scientific Party 2002).

Site 1202B (Huang et al. 2005; Wei et al. 2005), yielding in an unprecedented sedimentation rate of ca. $4 \mathrm{~m} \mathrm{kyr}^{-1}$. Within the context of the main objectives, this study aims to generate a preliminary, but still millennial scale resolution record of $U_{37}^{K^{\prime}}$ SST for this site. The $U_{37}^{K^{\prime}}$ method is now widely used for paleo-SST reconstruction (Zhao et al. 1995; Müller et al. 1998; Kienast et al. 2001), and is well suited for high-resolution records due to the relatively high sample throughput. This SST record is then used as a proxy to estimate the magnitude of tropical western Pacific SST decrease during the last glacial phase and to infer the SST variability of the Kuroshio's source region. The SST record is also compared with a $\delta{ }^{18} \mathrm{O}$ record of the planktic foraminifera Neogloboquadrina dutertrei in order to estimate the timing of SST changes during the last glacial/interglacial transition with regard to global ice volume changes. 


\section{MATERIALS AND METHODS}

Samples were taken at approximately 1.5 m intervals. Wei et al. (2005) have been able to generate a planktonic oxygen isotope record, indicating continuous deposition for the top $110 \mathrm{mof}$ the core, corresponding to the last $28 \mathrm{kyr}$. The age model was established based on 11 AMS ${ }^{14} \mathrm{C}$ dates, which showed neither age reversals, nor detectable gaps for this interval (Wei et al. 2005).

The samples were stored in a cold room at $5^{\circ} \mathrm{C}$ until they were freeze-dried before laboratory analysis. The method of Villanueva et al. (1997) was used for the $U_{37}^{\mathrm{K}}$ analysis because ODP Site 1202B samples typically contain large amount of terrigenous components. About 5 grams of powdered samples were extracted by ultrasonication using $8 \mathrm{ml}$ dichloromethane (DCM) and methanol (3:1, by volume). The supernatant was then transferred to another test tube. This extraction step was carried 4 times until the supernatant appeared to be colorless. The combined supernatants were dried with $\mathrm{N}_{2}$ gas.

A hydrolysis step was performed next in order to hydrolyze and remove some terrigenous wax esters in the samples and to allow for easier GC quantification of the alkenones. About $4 \mathrm{ml} \mathrm{KOH}$ solution $(5 \% \mathrm{KOH}$ in methanol) was added to each dried residue, followed by sonication for up to 10 minutes 3 times, and left at room temperature overnight to complete the hydrolysis reaction (Villanueva et al. 1997). The neutral lipids were extracted with $3.5 \mathrm{ml}$ hexane three times and the supernatants were transferred to a test tube and dried with $\mathrm{N}_{2}$ gas. The rest of the procedure is described in Zhao et al. (1995). Preliminary separation of the lipid classes was carried out by silica gel chromatograph and eluted with hexane, DCM and methanol, with the alkenones retained in the DCM fractions. After adding $\mathrm{C}_{36} n$-alkane as an external standard, the DCM fractions were derivatized with $40 \mu \mathrm{l}$ DCM and $40 \mu \mathrm{l}$ bis(trimethyl-silyl) trifluoro-actetamide (BSTFA) for 1 hour at $80^{\circ} \mathrm{C}$. Excess BSTFA and DCM were blown down with $\mathrm{N}_{2}$ gas and the residues were re-dissolved in iso-octane for $\mathrm{GC}$ measurements. The identification of alkenones was achieved by comparing their GC retention times with those of the synthesized authentic compounds. Quantification of the alkenones was calculated by GC peak integration and ratioing them to those of the internal and external standards. The Müller et al. (1998) equation was used for SST calculation: $\mathrm{U}_{37}^{\mathrm{K}}=0.033 \mathrm{~T}+0.044$. A typical GC trace is shown in Fig. 2.

\section{RESULTS AND DISCUSSIONS}

\subsection{SST Variability of the Last $28 \mathrm{kyr}$.}

The $\mathrm{U}_{37}^{\mathrm{K}^{\prime}}$ SST record for the top $110 \mathrm{~m}$ of the core is presented in Fig. 3. The record has a SST range of 20 to $28^{\circ} \mathrm{C}$, but most of the data fall within 22 and $27^{\circ} \mathrm{C}$. We need to briefly discuss the quality of this record before interpreting it. One potential problem for this core is the high terrigenous input. The upper $110 \mathrm{~m}$ of the core was mostly fine-grained clay and silt with mostly in situ foraminiferal species (Huang et al. 2005). Below this depth, coarser grained sandy layers occurred frequently (Fig. 3), indicating significant input of upper slope or shelf 


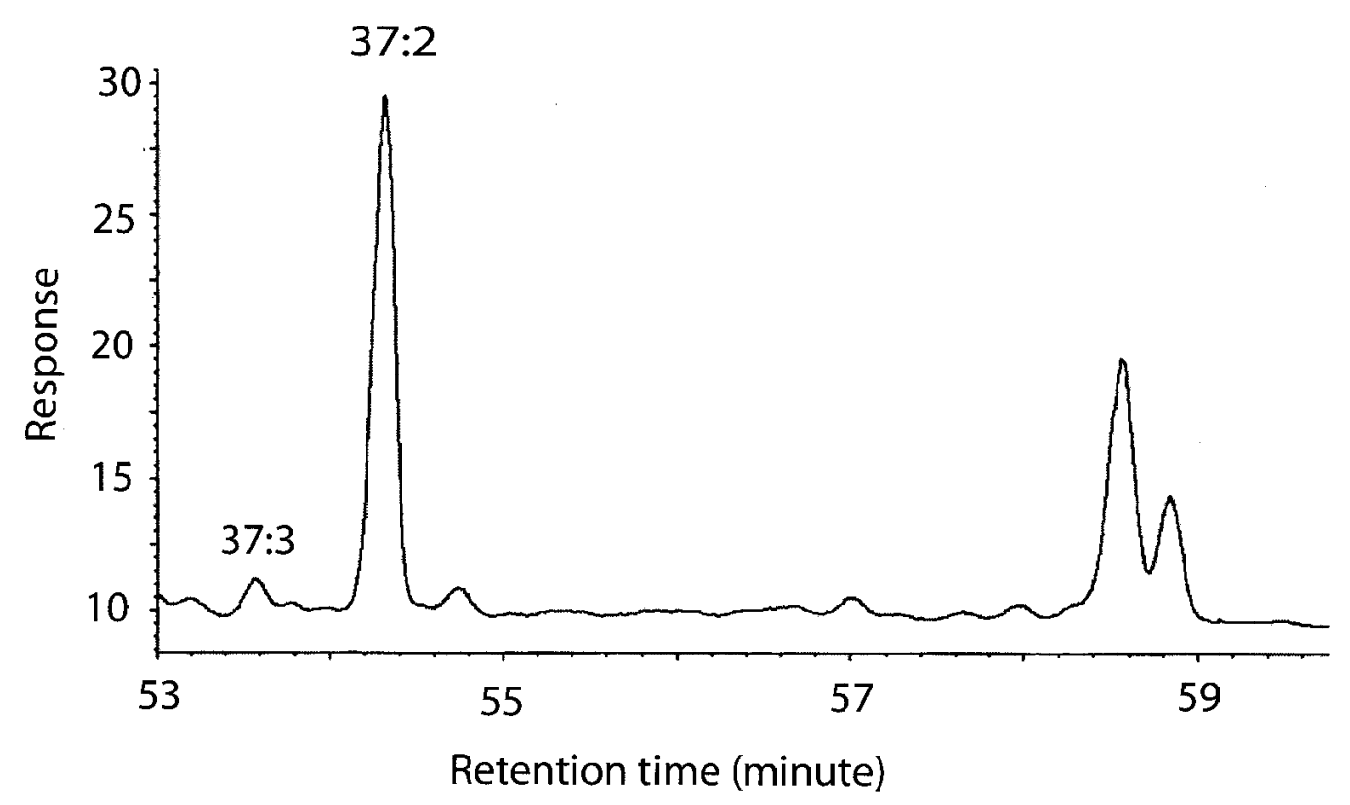

Fig. 2. A partial gas chromatogram showing the separation and retention times of the alkenones for a sample from the Holocene of ODP Site 1202B. 37:3 and 37:2 present the peaks for the $\mathrm{C}_{37: 3}$ and $\mathrm{C}_{37: 2}$ alkenones.

materials transported by turbidity currents or other unidentified processes. For this reason, only samples from the top $110 \mathrm{~m}$ of the core were analyzed. Another problem is the potential interferences of terrigenous organic compounds on the alkenone analyses. While terrigenous materials did not contribute any alkenones, they do present some analytical challenges. However, the procedure seems to produce good GC baseline separation for the alkenones (Fig. 2) and ensure good quality data. The late Holocene $\mathrm{U}_{37}^{\mathrm{K}} \mathrm{SST}$ value of ca. $27^{\circ} \mathrm{C}$, which matches today's SST for this region, is another indication that the $U_{37}^{K}$ method could be applied to this core.

This SST record is plotted against age (Wei et al. 2005) in Fig. 4a, along with the $\delta^{18} \mathrm{O}$ record of Neogloboquadrina dutertrei. Average low SST for the glacial period was $22.5^{\circ} \mathrm{C}$, and the average for the Holocene was $27^{\circ} \mathrm{C}$, hence yielding a glacial and Holocene SST difference of $4.5^{\circ} \mathrm{C}$. Except for one point, the SST during the last glacial maximum (LGM, 23 - $18 \mathrm{ka}$ ) was warmer than that of the deglaciation $(13-10 \mathrm{ka})$. However, the sampling resolution was lower for the LGM. There were a few large millennial scale SST oscillations $\left(2-4^{\circ} \mathrm{C} \mathrm{kyr}^{-1}\right)$ during the glacial period, but Holocene SST variations were smaller, except for the large change around $2-1.5 \mathrm{ka}$. Based on this age model, the deglaciation SST increase was $5^{\circ} \mathrm{C}$, which started around $13 \mathrm{ka}$ and reached average Holocene values around $8 \mathrm{ka}$, and noticeably the absence of the Younger Dryas cold reversal event in this record.

The $5^{\circ} \mathrm{C}$ deglaciation warming is conspicuously large for this tropical site, compared with previous records. The $\mathrm{U}_{37}^{\mathrm{K}}$ SST record from the tropical western Pacific revealed only ca. $1^{\circ} \mathrm{C}$ 


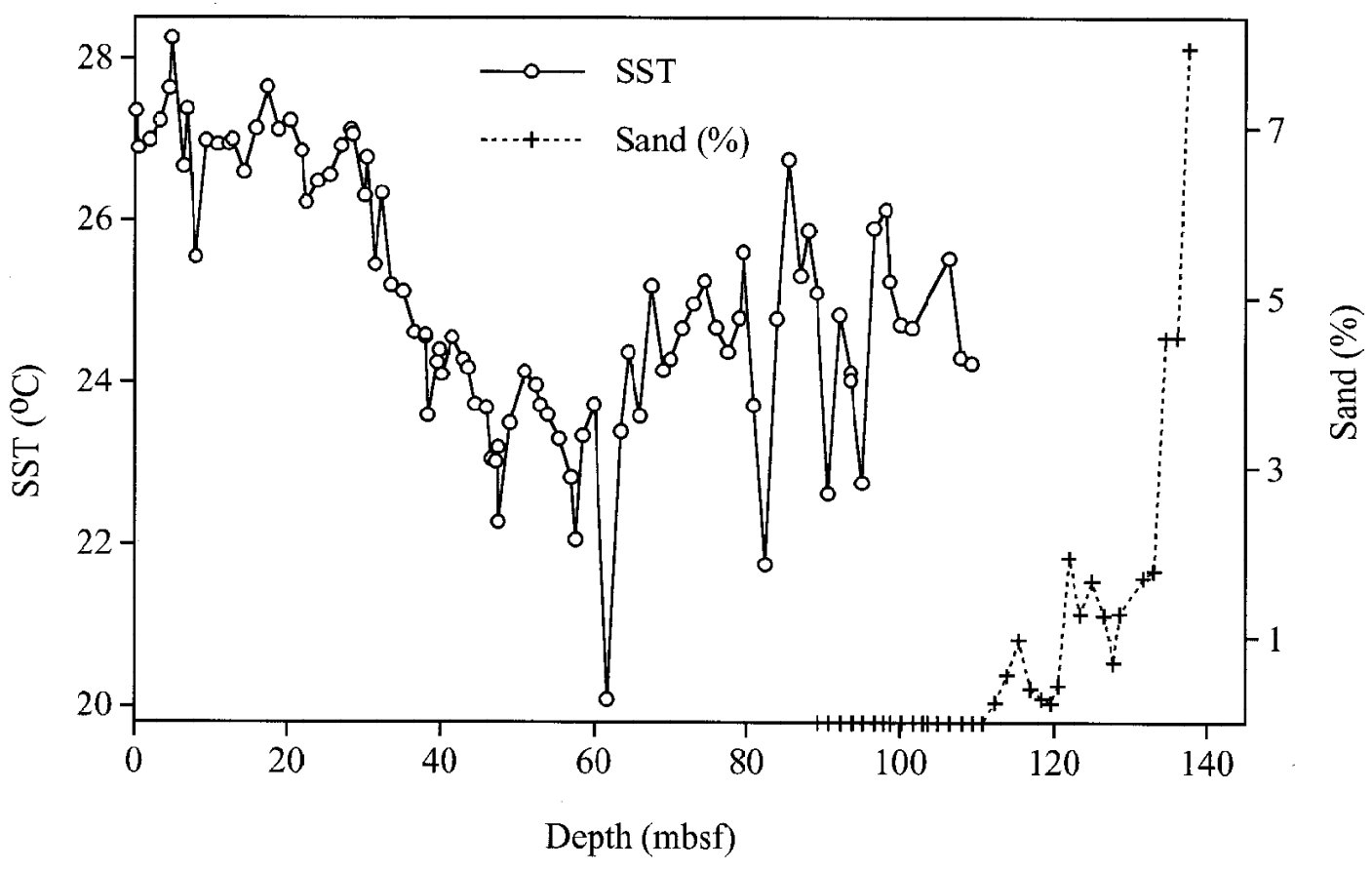

Fig. 3. SST (solid line and open circles) and sand\% (dashed line and plus) versus depth for ODP Site 1202B. $\mathrm{U}_{37}^{\mathrm{K}^{\prime}}$ SST was only measured for the top $110 \mathrm{~m}$ of the core, while sand $\%$ for the top $90 \mathrm{~m}$ was below detection limit (Huang et al. 2005).

warming (Ohkohchi et al. 1994), while $\mathrm{Mg} / \mathrm{Ca}$-based SST records suggest a $2-4^{\circ} \mathrm{C}$ warming for the western Equatorial Pacific (Lea et al. 2000; Rosenthal et al. 2003; Visser et al. 2003). Foraminiferal assemblage-based annual SST indicated a lesser warming for two cores just east of Site 1202B (Ujiié et al. 2003), but a comparable warming for a core from the middle Okinawa Trough (Li et al. 2001). For the South China Sea (SCS) where many SST records were reconstructed using various proxies, the deglaciation warming was generally $2-3^{\circ} \mathrm{C}$ for the southern SCS (Wang et al. 1999; Kienast et al. 2001; Chen et al. 2003), while it was around $4^{\circ} \mathrm{C}$ for the northern SCS (Huang et al. 1997; Wei et al. 1998; Wang et al. 1999). Thus, the ODP Site 1202B SST change in the southern Okinawa Trough was similar to or more pronounced than other marginal seas of the western Pacific, where the SST variations were influenced by the strengthened winter monsoon and coastal ocean current during the glacial period (Huang et al. 1997; Wang et al. 1999). On the other hand, the open ocean tropical western Pacific was mostly dominated by large-scale ocean circulation and ENSO. 
(a) Age (ka)

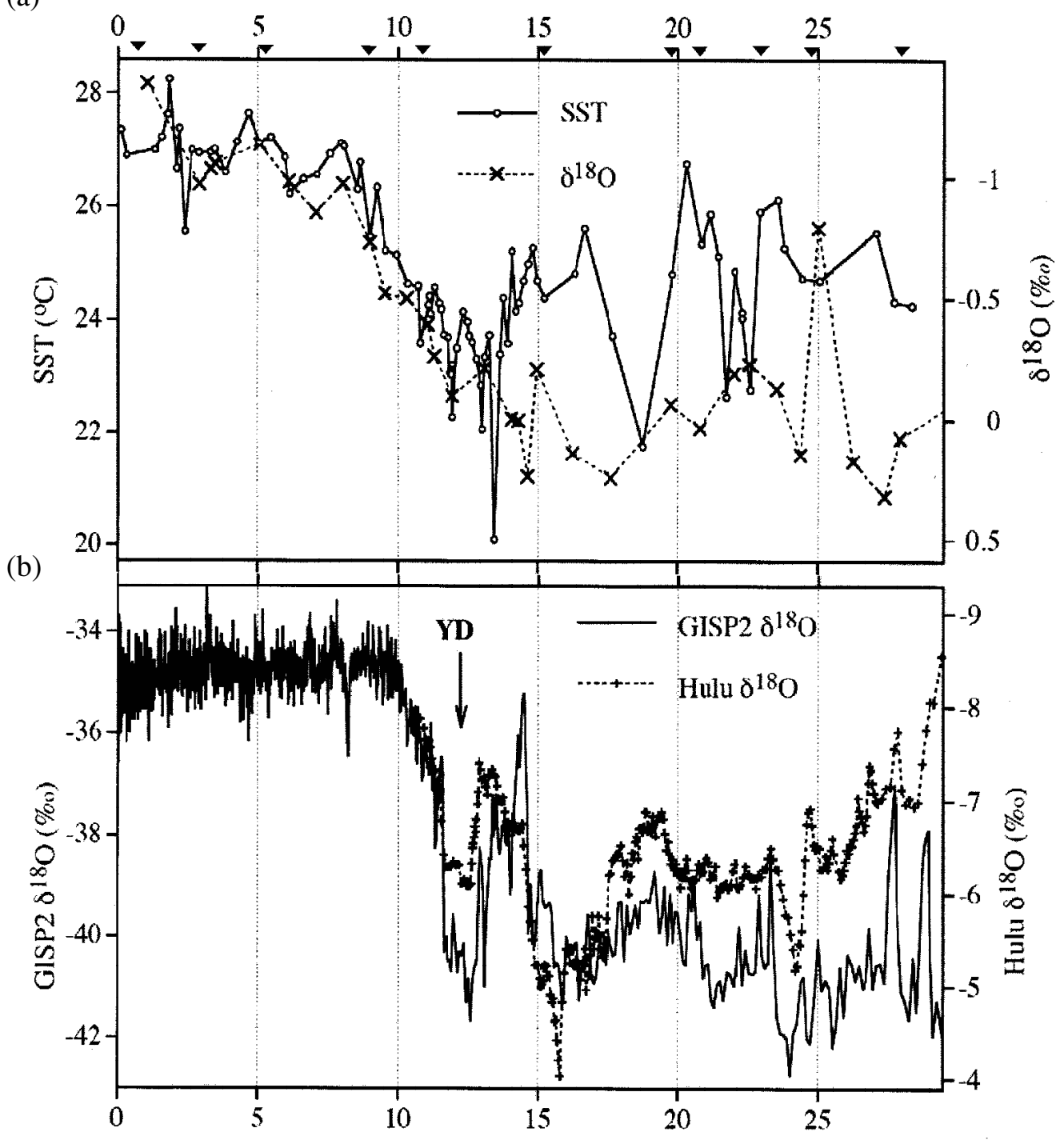

Age (ka)

Fig. 4. (a) $\mathrm{U}_{37}^{\mathrm{K}} \mathrm{SST}$ (solid line and open circles) and $\delta^{18} \mathrm{O}$ of the planktonic foraminifera Neogloboquadrina dutertrei (dashed line and cross) versus age for ODP Site 1202B. The solid triangle symbols on the top panel indicate the $11 \mathrm{AMS}{ }^{14} \mathrm{C}$ age control points. (b) $\delta{ }^{18} \mathrm{O}$ records of GISP2 (solid line) and Hulu Cave (dashed line and plus) versus age for the last $30 \mathrm{kyr}$. YD and the arrow indicate the Younger Dryas cold event in the records. 


\subsection{Timing of the Last Deglaciation Warming}

One important approach to understanding the mechanisms of climate change is the spatial relationship of the timing of major climate transitions, such as during the last deglaciation and transitions associated with the major orbital-scale cycles (Herbert et al. 2001). Two methods are generally employed to decipher the phase relationship among the different proxy records. The first one assumes that foraminiferal $\delta{ }^{18} \mathrm{O}$ records mainly reflect continental ice volume/ sea level changes. Hence, the comparison of other proxy records with the $\delta^{18} \mathrm{O}$ record from the same core provides a temporal measure with regard to global ice volume change. Recent studies using this approach show that the last deglaciation SST warming in both the western and eastern Equatorial Pacific led ice volume change by several thousands year, but was almost synchronous with Antarctic warming (Lea et al. 2001; Visser et al. 2003). These observations can be taken to indicate that the Equatorial Pacific region was responding early to the Southern Hemisphere deglaciation, with important implications regarding the role of the tropical Pacific in driving the global glacial-interglacial cycles, possibly involving a mechanism similar to super ENSOs (Koutavas et al. 2002; Stott et al. 2002; Visser et al. 2003). Early deglaciation warming was also recorded along the California margin of the eastern Pacific (Herbert et al. 2001), but a delayed warming was observed at the mid-latitude region of the western Pacific (Zhao and Huang 2003; Yamamoto and Irino 2003). The spatial variability of these phase relationships suggests different controlling mechanisms for SST changes.

The second method for revealing the phase relationship of climate change from different regions is the direct chronological comparison of well-dated records. Chinese loess climate records (Porter and An 1995), $\delta{ }^{18} \mathrm{O}$ of stalagmite from Hulu Cave (Wang et al. 2001) and SST from the SCS (Kienast et al. 2001, 2003) all reveal that the deglaciation changes were generally in phase with global ice volume change and northern hemisphere high latitude climate changes. These records indicate that these changes were mainly driven by ice volume changes and atmospheric circulation, especially the monsoons.

Within the uncertainties afforded by our records, the SST change during the last deglaciation seems to be synchronous with ice volume change indicated by the $\delta^{18} \mathrm{O}$ record (Fig. 4a). If confirmed by high-resolution records, this indicates that the tropical/subtropical western Pacific behaved differently compared with the Equatorial and mid-latitude western Pacific. A latitudinal shift in the deglaciation timing was also observed in the eastern Pacific (Lea et al. 2000; Herbert et al. 2001). Thus, the low latitude deglaciation warming displays different temporal and spatial patterns along the two sides of the Pacific. One reasonably clear fact is that the ODP Site 1202B deglaciation did not respond to the Southern Hemisphere warming as the Equatorial Pacific did (Lea et al. 2000).

Since the age model for our record is well constrained by $11 \mathrm{AMS}{ }^{14} \mathrm{C}$ dates, a direct comparison with other well-dated records can afford more insight into the forcing mechanisms for this site. The SST record is compared with the GISP2 ice core $\delta^{18} \mathrm{O}$ and the Hulu stalagmite $\delta^{18} \mathrm{O}$ (Fig. 4b). The ODP 1202B SST record reveals some differences compared with these two continental climate records. Deglaciation warming started at ca. $13 \mathrm{ka}$ in the SST record, while it started at ca. $15 \mathrm{ka}$ in both the Hulu and GISP $2 \delta^{18} \mathrm{O}$ records. The SST increase was more or less a one step process, establishing Holocene values at ca. $7.5 \mathrm{ka}$. On the 
other hand, the Hulu and GISP2 $\delta{ }^{18} \mathrm{O}$ records show the clear negative excursion at $11-12 \mathrm{ka}$ associated with the Younger Dryas cooling. One explanation for these differences may lie in the uncertainties of the age models. It is important to note that there is a SST minimum around $19 \mathrm{ka}$, but the record for this time interval is of low-resolution. If confirmed, one might argue that SST also went through a two-step deglaciation. In this case, it might be reasonable to correlate this SST minimum with the $\delta^{18} \mathrm{O}$ minimum of Hulu and GISP-II at $15-17 \mathrm{ka}$, which can be interpreted such that the first step deglaciation at Site 1202 led the ice core and continental monsoon record. A high resolution record with more detailed age control from Site 1202 will help to resolve the lead/lag phase relationship among these climate records.

Another significant control on Site 1202B SST is sea level changes. Today, the site is within the main pathway of the Kuroshio. During the last glacial period, the lowering of the sea level by up to $120 \mathrm{~m}$ (Fairbanks 1989) and the exposure of the wide continental shelf region of the East China Sea (including the Taiwan Strait) would have had significant impact on the pathway of the Kuroshio, reducing its influence. In addition, Site 1202B would be much closer to the coastline and hence subjected to the stronger influence of the coastal current. Furthermore, the East Asia winter monsoon would also influence this region's SST, analogous to the situation in the SCS. The first pulse of ice melting and sea level rises occurred at $19 \mathrm{ka}$, but the second and more dramatic pulse occurred at $15 \mathrm{ka}$ (Hanebuth et al. 2000; Lambeck 2002). This change might have altered the Kuroshio's pathway to play some role in the deglaciation increase in SST at Site 1202B. Indeed, it has been suggested that the Kuroshio was forced eastward at low latitude due to the formation of a hypothetical land bridge between Taiwan and the southern Ryukyu Arc which prohibited its flow into the Okinawa Trough (Ujiié and Ujiié 1999; Ujiié et al. 2003).

\section{SUMMARY}

In summary, a millennial-scale SST record has been generated for ODP Site 1202B, which shows a glacial-interglacial SST difference of $5^{\circ} \mathrm{C}$. This difference is larger than SST changes at similar latitudes of the open Pacific Ocean, but is similar in amplitude with SST changes of the western Pacific marginal seas, such as the northern SCS. Based on the ${ }^{14} \mathrm{C}$ age model, the deglaciation SST warming at this site was synchronous with ice volume changes reflected by planktonic oxygen isotope record, but lagged the warming in Greenland's ice core record and in the monsoon record from the Hulu Cave of Eastern China. The enhanced glacial cooling for this site could have been caused by several factors, including the changed strength and pathway of the Kuroshio due to sea level variation, the cooling by the stronger winter monsoon, and the influence of the coastal current due to coastline shift. This is in agreement with modeling results suggesting that changes in monsoon circulation and equatorial wind fields dominate tropical climate history (Prell and Kutzbach 1987). The successful application of the $\mathrm{U}_{37}^{\mathrm{K}}$ technique to this core demonstrates that a decadal-scale climate record is achievable with the ca. $4 \mathrm{~m} \mathrm{kyr}^{-1}$ sedimentation rate.

Acknowledgements We thank the curators of the Ocean Drilling Program for making samples available. This research was supported by the National Science Council of Taiwan, R.O.C. 
(NSC91-2816-M006-0001-6) and the NCKU-NSYSU Research Center of Ocean Environment and Technology.

\section{REFERENCES}

Cane, M. A., 1998: A role for the tropical Pacific. Science, 282, 59-61.

Chen, M. T., L. Shiau, P. Yu , T. Chiu , Y. Chen, and K. Wei , 2003: 500000-year records of carbonate, organic carbon and foraminiferal sea-surface temperature from the southeastern South China Sea (near Palawan Island). Palaeogeog., Palaeoclimatol., Palaeoecolog., 197, 113-131.

Fairbanks, R. G., 1989: A 17,000-year glacio-eustatic sea level record: Influence of glacial melting rates on the Younger Dryas event and deep-ocean circulation. Nature, 342, 637-642.

Fan, K. L., 1985: CTD measurements in the seas around Taiwan during 1977-1983. Inst. Ocedanogr., N.T.U., Special Publication, 51, 377 pp.

Hanebuth, T., K. Stattegger, and P. Grootes, 2000 : Rapid flooding of the Sunda Shelf: A lateglacial sea-level record. Science, 288, 1033-1035.

Herbert, T., J. Schuffert, D. Andreasen, L. Heusser, M. Lyle, A. Mix, A. C. Ravelo, L. D. Stott, and J. C. Herguera, 2001: Collapse of the California Current During Glacial Maxima Linked to Climate Change on Land. Science, 293, 71-76.

Hoerling, M., J. Hurrell, and T. Xu, 2001: Tropical origins for recent North Atlantic climate change. Science, 292, 90-92.

Hoerling, M., and A. Kumar, 2003: A perfect ocean for drought. Science, 299, 691-694.

Huang, C. Y., Y. L. Chiu, and M. Zhao, 2005: Sedimentological features of silt and sand depositions in ODP Site 1202, Leg 195, off NE Taiwan.Terr. Atmos. Ocean. Sci., 16, $19-44$.

Huang, C. Y., S. F. Wu, M. Zhao, M. T. Chen, C. H. Wang, X. Tu, and P. B. Yuan, 1997 : Surface ocean and monsoon climate variability in the South China Sea since the last glaciation. Marine Micropaleontol., 32, 71-94.

Kienast, M., S. Steinke, K. Stattegger, and S. E. Calvert, 2001: Synchronous tropical South China Sea SST change and Greenland warming during deglaciation. Science, 291, 21322134.

Kienast, M., T. J. J. Hanebuth, C. Pelejero, S. Steinke, 2003 : Synchroneity of meltwater pulse 1a and the Bølling warming: new evidence from the South China Sea. Geology, 31, 67-70.

Koutavas, A., J. Lynch-Stieglitz, T. M. Marchitto, and J. P. Sachs , 2002 : El Niño-like pattern in Ice Age tropical sea surface temperature. Science, 297, 226-230.

Lambeck, K., Y. Yokoyama, and T. Purcell, 2002: Into and out of the Last Glacial Maximum: sea-level change during oxygen isotope stages 3 and 2. Quat. Sci. Rev., 21, 343-360.

Lea, D. W., D. K. Pak, and H. J. Spero, 2000: Climate impact of late Quaternary Equatorial 
Pacific sea surface temperature variations. Science, 289, 1719-1724.

Li, B., Z. Jian, and P. Wang, 1997: Pulleniatina obliquiloculata as a paleoceanographic indicator in the southern Okinawa Trough during the last 20,000 years.Mar. Micropaleontol., 32, 59-69.

Li, T., Z. Liu , M. A. Hall, S. Berne, Y. Saito, S. Cang, Z. Cheng, 2001: Heinrich event imprints in the Okinawa Trough: evidence from oxygen isotope and planktonic foraminifera. Palaeogeog., Palaeoclimatol., Palaeoecolog., 176: 133-146.

Müller, P. J., G. Kirst, G. Ruhland , I. von Storch, and A. Rosell-Mele, 1998: Calibration of the alkenone paleotemperature index $\mathrm{U}_{37}^{\mathrm{K}}$ based on core-tops from the eastern South Atlantic and the global ocean $\left(60^{\circ} \mathrm{N}-60^{\circ} \mathrm{S}\right)$. Geochim. Cosmochim. Acta., 62, 17571772.

Nitani, H., 1972: Beginning of the Kuroshio. In: Stommol, H. and K. Yoshida, (Eds.) Kuroshio, Univ. Washington Press, Seattle, 129-163.

Ohkohchi, N., K. Kawamura, T. Nakamura, and A. Taira , 1994 : Small changes in the sea surface temperature during the last 20,000 years: Molecular evidence from the western tropical Pacifc. Geophys. Res. Lett., 21, 2207-2210.

Pierrehumbert, R., 2000: Climate change and the tropical Pacific: The sleeping dragon wakes. Proc. Nat. Acad. Sci., 97, 1355-1358.

Porter S. C., and Z. An, 1995: Correlation between climates events in the North Atlantic and China during the last glaciation. Nature, 375, 305-308.

Prell, W. L., and J. E. Kutzbach, 1987: Monsoon variability over the past 150,000 years.J. Geopgys. Res., 92, 8411-8425.

Rosenthal, Y., D. W. Oppo, and B. K. Linsley, 2003: The amplitude and phasing of climate change during the last deglaciation in the Sulu Sea. Geophy. Res. Lett., 30, doi:10. 1029/2002GL016612.

Sawada, K., and N. Handa, 1998: Variability of the path of the Kuroshio ocean current over the past 25,000 years. Nature, 392, 592-595.

Shipboard Scientific Party, 2002. Site 1202. In Salisbury, M.H., Shinohara, M., Richter, C., et al., Proc. ODP, Init. Repts., 195, 1-46 [CD-ROM]. Available from: Ocean Drilling Program, Texas A\&M Unive., College Station TX 77845-9547, USA.

Stott, L., C. Poulsen, S. Lund, and R. Thunell, 2002: Super ENSO and global climate oscillations at millennial time scales. Science, 297, 222-226.

Ujiié, H., and Y. Ujiie, 1999: Late Quaternary course changes of the Kuroshio Current in the Ryukyu Arc region, northwestern Pacific Ocean. Marine Micropaleontol., 37, 23-40.

Ujiié, Y., H. Ujiié, A. Taira, T. Nakamura, and K. Oguri, 2003: Spatial and temporal variability of surface water in the Kuroshio source region, Pacific Ocean, over the past 21,000 years: evidence from planktonic foraminifera. Marine Micropaleontol., 49, 335-364.

Villanueva, J., C. Pelejero, and J. O. Grimalt, 1997: Clean-up procedures for the unbiased estimation of $\mathrm{C}_{37}-\mathrm{C}_{39}$ alkenone sea surface temperatures and terrigenous $n$-alkane inputs in paleoceanography. J. Chromatogr., 757, 145-151.

Visser, K., R. Thunell, and L. Stott, 2003: Magnitude and timing of temperature change of the Indo-Pacific warm pool during deglaciation. Nature, 421, 152-155. 
Wang, L., M. Sarnthein, H. Erlenkeuser, J. Grimalt, P. Groote, S. Heiling, E. Ivanova, M. Kienast, C. Pelejero, and U. Pflaumann, 1999: East Asian monsoon climate during the late Pleistocene: High-resolution sediment records from the South China Sea.Mar. Geol., 156, 245-284.

Wang, Y. J., H. Cheng, R. L. Edwards, Z. S. An, J. Y. Wu, C. C. Shen, and J. A. Dorale, 2001: A high-resolution absolute-dated late Pleistocene monsoon record from Hulu Cave, China. Science, 294, 2345-2348.

Wei, K. Y., M. Y. Lee, W. Duan, C. Chen, and C. H. Wang, 1998: Paleoceanographic change in the northeastern South China Sea during the last 15000 years. J. Quat. Sci., 13, 5564.

Wei, K. Y., H. S. Mii, and C. Y Huang, 2005: Age model and oxygen isotope stratigraphy of Site ODP1202 in the Southern Okinawa Trough, northwestern Pacific. Terr. Atmos. Ocean. Sci., 16, 1-17.

Yamamoto, M., and T. Irino, 2003: Orbital-scale ENSO-like variability in the mid-latitude North Pacific and its regional influences on climate changes in the East Asia, abstract in "Monsoon evolution and tectonics-climate linkage in East Asia and its marginal seas during the late Cenozoic". IGCP-476 symposium, Tokyo.

Yuan, Y., Y. Liu , C. T. Liu , and J. Su, 1998: The Kuroshio east of Taiwan and the currents east of the Ryukyu-gunto during October of 1995. Acta Oceanol. Sinica, 17, 1-13.

Zhao, M., N. A. S. Beveridge, N. J. Shackleton, M. Sarnthein, and G. Eglinton, 1995: Molecular stratigraphy of cores off Northwest Africa: Sea surface temperature history over the last 80 ka. Paleoceanogr., 10, 661-675.

Zhao, M and C.Y. Huang, 2003: Millennial scale variability of western Pacific SST and Kuroshio current: evidence of precessional forcing. Abstract in "Monsoon evolution and tectonics-climate linkage in East Asia and its marginal seas during the late Cenozoic", IGCP-476 symposium, Tokyo. 